\title{
Application of Digital Innovation with a Freemium Business Strategy to Increase Sales of Accounting Software in Indonesia
}

\author{
Gandy Wahyu Maulana Zulma ${ }^{1, *}$ Erida $^{2}$ \\ ${ }^{12}$ Faculty of Economics and Business, Jambi University) \\ *Corresponding author.Email: maulanagandi25@unja.ac.id
}

\begin{abstract}
This study aims to provide empirical evidence about the strategy of freemium software which is a new business model in the digital era by applying the Dual Mediation Hypothesis (DMH Model) to investigate the effects of the freemium strategy as a promotional tool to increase user interest in purchasing premium licensed accounting software at Indonesia. This study uses 206 samples of respondents from various backgrounds, such as consultants, business owners, managers, and employees who use accounting software in business activities in Indonesia. Based on the discussion, the results of the research show that freemium software can be a good marketing strategy for software developers. Through the free version of the software provided to users, it can change user behavior to switch to a complete premium version, so it can effectively increase sales of accounting software in the current digital era.
\end{abstract}

Keywords: Accounting Software Premium, Dual Mediation Hypothesis, Freemium Software.

\section{INTRODUCTION}

Increasing competition in the current accounting software sales has made software developers implement freemium software strategies to attract potential users to buy premium software. According to Wagner, T.M., T.M., et al. [1], the freemium strategy has become popular in recent years and is claimed as an answer to the problem of how to get income from internet networks.

Basic Concept of Freemium is a combination of free and premium software versions; premium users finance non-premium users [1]. Lyons, K., et al. [2] also explained that the success of the freemium strategy could also be seen in the Intuit software developer who published TurboTax, which is a taxation software in the US. Intuit provides free software in the standard version but will be charged if the user wants to use the premium version of the software. As a result, about $70 \%$ of users in the US choose to pay for the premium version. Intuit also released accounting software, Quick books, which is also a freemium software. Quick books have been circulating widely in
Indonesia, along with many other freemium software such as Accurate and MYOB.

However, the characteristics of software users in the US and Indonesia are very different. Based on research conducted by Business Software [3] that the level of pirated PC software circulation in Indonesia reached $86 \%$ with a value of USD 1,467, whereas in the US it was only $19 \%$. In other words, the characteristics of software users in Indonesia like cheap software, not even paid (lifetime free), moreover pirated software is still more affordable than licensed software.

For users, the high costs incurred to purchase software becomes a consideration in choosing a credible accounting software that can be integrated with user information systems and technology. Although currently, users need accounting software as a tool for creating financial reports cost efficiency is still required for users, both small and medium-sized companies, freelancers / financial statement consultants, and other individual users to achieve maximum profits.

In a previous study by Wagner, T.M., et al. [1] found that freemium software can increase the 
probability of a user purchasing premium music software licensed in the US. Albert, L.J., et al. [4] added in his research found that software purchase is influenced by two main factors, namely the frequency of use and the value obtained by users (perceived value) of the software.

The existence of this freemium strategy makes this topic interesting to study. However, this has not been much observed among researchers in information systems, especially in the field of accounting information systems. As far as the literature review has been done, there has been no empirical study in Indonesia that proves that freemium software can increase the user's desire to purchase a licensed version of premium accounting software, which will ultimately be used by these users in preparing financial statements.

The main contribution in this research is: first, to provide empirical evidence about the impact of the freemium software strategy that affects user interest in purchasing licensed premium accounting software. Second, in this study, using a questionnaire that has been adjusted for re-search in Indonesia and also uses the DMH (Dual Mediation Hypothesis) model that has been used by several world researchers, such as Wagner, T.M., et al. [1], and Lopez, I., \& Ruiz, S.

\section{LITERATURE REVIEW AND HYPOTHESIS DEVELOPMENT}

\subsection{Freemium Business Strategy}

Wagner, T.M., et al. [1] explained that Freemium comes from a combination of free and premium words that were first introduced by Wilson, F. [6]. The concept of freemium began in the 1980s, where software developers gave free versions of software to users in the hope that users would upgrade the software to premium [7]. Lyons, K., et al. [2] suggested that if a software developer uses this strategy, it is likely that only $1 \%$ of users will buy the premium version, but because the cost of making the software is low, $1 \%$ of the paying users can cover the costs of $99 \%$ of non-paying users. Besides, software developers also get other in-come from advertising that can cover the cost of making software.

The Freemium strategy has become increasingly popular lately used by software developers such as Adobe Photoshop, Microsoft Office, and Skype that provide free versions until the trial period runs out, that is after 30 or 60 days. After the period expires, the software will be locked, and the user must enter the registration number if you want to re-access it [1][8]. This strategy has also been used by software developers who develop software in accounting, such as MYOB, Quick books, and Accurate. So that accounting software users can learn the contents of the software through the free version before buying the premium version.

\subsection{DMH Model (Dual Mediation Hypothesis)}

Dual Mediation Hypothesis (DMH) is a model that can be used to investigate the effect of a freemium strategy, namely the provision of free software as a promotion of software developers that can support users to purchase premium software [1]. DMH also considers the existence of direct and indirect influences that can influence user behavior [9]. This model has also been used in the research of Wagner, T.M., et al. [1], Lopez, I., \& Ruiz, S. [5], Cheng, H.K. \& Tang, Q.C. [10] Karson, E. J., \& Fisher, R. J. [11]. The DMH Model Framework can be seen in Figure 1.

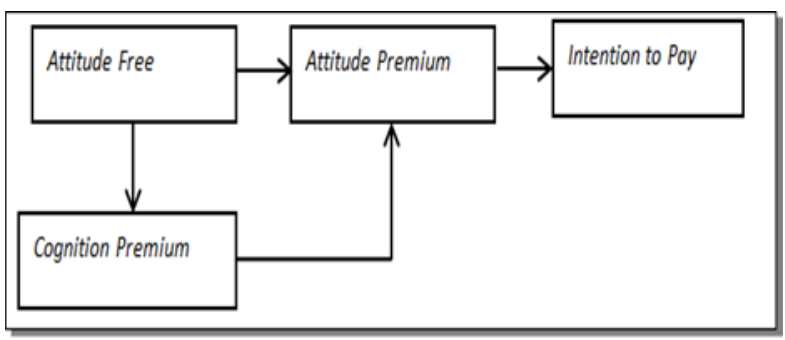

Figure 1 Dual Mediation Hypothesis Model (DMH)

\subsection{Hypothesis Development}

Using the DMH model, this study examines the influence of attitude-free software behavior on attitude toward premium software interest (attitude premium). Wagner, T.M., et al. [1] did not find a positive relationship between the behavior of interest in free software (attitude-free) to a behavior of interest in premium software (attitude premium). However, the free software version can be one of the promotions carried out by software developers to users that can influence users to use premium software, so that the behavior and interests of users will change from the free version to an interest in premium software.

H1: Behavior of interest in free software (Attitude Free) has a positive effect on behavior-al interest in premium software (Attitude Premium)

According to Wagner, T.M., et al. [1], in conditions where users have a tendency to be forced to spend money to buy software, recognition of the quality of a premium software is very important to influence the user's logic in buying software.

Furthermore, Wagner, T.M., et al. [1] explain that user recognition of better quality premium software can mediate the relationship between the behavior of users who are only interested in free software to change interest in premium software. Wagner, T.M., et al. [1] also found a positive relationship with interest in free software for premium recognition and also a positive relationship between premium recognition and interest in premium software. 
So, in accordance with the DMH model in this study, it is also seen the influence of the user's awareness of the difference in premium version facilities that is more than complete the free version in influencing user interest and behavior towards premium software.

H2a: The interest of users of the free version of the software (attitude-free) has a positive effect on user awareness of differences in the premium version of the facility which is more than complete the free version (cognition premium)

H2b: User awareness of differences in the premium version of the facility which is more than complete the free version (cognition premium) has a positive effect on the behavior to use the premium version (attitude premium)

If the user already has an interest in premium software, of course, this will affect the user's decision to buy premium software. Wagner, T.M., et al. [1] also revealed a positive relationship between interest in premium software and the decision to purchase premium software.

Thus, the decision to buy licensed accounting software is influenced by user interest and behavior towards premium software. As mentioned in the previous sub chapter, the user's interest in buying software can be influenced by satisfaction in using free software through personal experience and information obtained from other sources.

H3 : Behavior and interest to use the premium version (attitude premium) has a positive effect on the level of probability of users in buying premium versions of licensed accounting software (intention to pay).

Wagner, T.M., et al. [1] suggested that software developers try to minimize the similarity of content between free software and the premium version. Because if there is a big equation, it is feared that users are not interested in buying the premium version of the software. As a result, users will continue to use free software continuously even if only for a limited period (free trial version). So in this study, the effect of different levels of free and premium software content was tested on the interests and behavior of users regarding the use of free software.

H4: The level of gap between free and premium content (perceived premium fit) has a positive effect on the interests and behavior of users of the free version of the software (attitude-free).

In terms of choosing the software to be used, users can use the free software facility provided by the software developer. However, if the user wants to get software content that is better quality and has premium content, then the user is required to pay a fee to the software developer based on applicable regulations, such as payment of the fee made once a year to the software developer.

If the user is aware of the quality of the software that is obtained depending on the amount of the price of the software, then the actual price of the software can affect the user's behavior towards recognition of the quality of the content of premium software. Wagner, T.M., et al. [1] also found a positive relationship between software prices and recognition of premium quality.

H5 : The price level of software to be paid (perceived price value) has a positive effect on user awareness of the difference in the premium version of the more complete facilities than the free version (premium cognition).

\section{RESEARCH METHOD}

\subsection{Sample and Data Collection}

This study uses samples from primary data obtained through surveys by distributing questionnaires directly and electronically. The respondents consisted of practitioners, businessmen, and academics from all over Indonesia. Of the 500 questionnaires distributed, there were 206 return questionnaires that were eligible to be sampled in this study. A fairly high participation rate of $41.2 \%$ is expected to represent the perception of the population as a whole.

Table 1 shows that the number of respondents is quite scattered from various circles of Freemium software users in Indonesia such as the majority of respondents consisting of Employees (29.99\%), Business Owners (24.27\%), and Consultants (16.99\%). While the smallest number of Others $(9.22 \%)$ cannot be grouped in this study sample. This is done in order to obtain a valid data source so that conclusions can be drawn in general regarding the phenomenon of freemium software in Indonesia.

Table 1. Sample Observation

\begin{tabular}{|c|c|c|}
\hline Status & Quantity & $\%$ \\
\hline Consultant & 35 & 16.99 \\
\hline Business Owner & 50 & 24.27 \\
\hline Manager & 10 & 4.85 \\
\hline Employee & 60 & 29.13 \\
\hline Academics & 32 & 15.53 \\
\hline And Others & 19 & 9.22 \\
\hline Total & 206 & 100.00 \\
\hline
\end{tabular}

\subsection{Research Model}

This research is applied research by developing a DMH model (Dual Model Hypothesis) using the form of structural equation modelling partial least squares (SEMPLS) using Warp PLS software. Sholihin, M., \& Ratmono, D. [12] stated that in its development, SEM is divided into two types, namely covariance-based SEM 
(CB-SEM) and variance-based SEM or partial least squares (SEM-PLS).

Basically, the estimation results of the two models are not much different so that the SEM-PLS can be a good proxy for CB-SEM. The excess of SEM-PLS can still produce estimates even for small sample sizes and deviations from the assumption of multivariate normality. The model equation to test the hypothesis in this study is as follows:

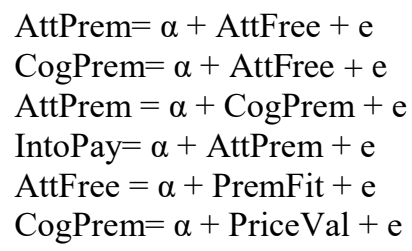

\section{Definition Variables}

AttFree = Attitude Free; user perceptions of interest in using free accounting software

AttPrem = Attitude Premium; user perception in interest in using premium accounting software

CogPrem $=$ Cognition Premium; user awareness related to differences in the facilities premium version is more than complete the free version

IntoPay = Intention to Pay; user perception in buying the premium version of licensed accounting software

PriceVal= Perceived Price Value; user perception about the amount of software prices

PremFit $=$ Perceived Premium Fit; user perception about the level of gap between free and premium content

\subsection{Operationalization Variables}

In this study there are six latent variables namely Price of Software (PriceVal), Difference of Free \& Premium Content (PremFit), Interest of Free Software (AttFree), Interest of Premium Software (AttPrem), User Awareness (CogPrem), and Interest in purchasing Premium Software (IntoPay).

Each latent variable is measured using observable variables, such as PriceVal (PV1, PV2, PV3), PremFit (PF1, PF2, PF3, PF4), AttFree (AF1, AF2, AF3, AF4), AttPrem (PF1, PF2, PF3, PF4), AttFree (AF1, AF2, AF3, AF4), AttPrem (PF1, PF2, PF3, PF4) AP1, AP2, AP3), CogPrem (CP1, CP2, CP3), and IntoPay (IP1, IP2, IP3,

IP4, IP4). Based on the validity and reliability test of the questionnaire indicators for the initial sample of 50 respondents, found several observational variables that are not feasible to be used such as variables PF3, PF4, AP3, CP1, and IP2. So it must be excluded from the research questionnaire statement.

\section{RESULTS AND DISCUSSION}

\subsection{Validity and Reliability}

According to Sholihin, M., \& Ratmono, D. [12] that there are two criteria in measuring whether the measurement model meets the requirements of convergent validity for reflective constructs namely the standard loading factor $(>0.7)$ and p-value $(<0.05)$. Based on the test of convergent validity for each indicator, the reflective construct has fulfilled the requirements (loading>0.7) and p-value $(<0.001)$.

Table 2. Standard Factor Loadings, AVE, and CR

\begin{tabular}{|c|c|c|c|c|c|}
\hline Construct & Item & $\begin{array}{l}\text { Standard Factor } \\
\text { Loadings }\end{array}$ & $\begin{array}{c}\text { Type } \\
\text { (as defined) }\end{array}$ & $\begin{array}{l}\text { Avg. var. extract } \\
\text { (AVE) }\end{array}$ & $\begin{array}{c}\text { Composite } \\
\text { reliability }(\mathrm{CR})\end{array}$ \\
\hline \multirow[t]{3}{*}{ PriceVal } & PV1 & .881 & Reflective & .791 & .919 \\
\hline & PV2 & .919 & Reflective & & \\
\hline & PV3 & .866 & Reflective & & \\
\hline \multirow[t]{2}{*}{ PremFit } & PF1 & .873 & Reflective & .762 & .865 \\
\hline & PF2 & .873 & Reflective & & \\
\hline \multirow[t]{4}{*}{ AttFree } & AF1 & .786 & Reflective & .608 & .861 \\
\hline & AF2 & .744 & Reflective & & \\
\hline & AF3 & .800 & Reflective & & \\
\hline & AF4 & .788 & Reflective & & \\
\hline \multirow[t]{2}{*}{ AttPrem } & AP1 & .924 & Reflective & .854 & .921 \\
\hline & AP2 & .924 & Reflective & & \\
\hline \multirow[t]{2}{*}{ CogPrem } & $\mathrm{CP} 2$ & .836 & Reflective & .698 & .822 \\
\hline & $\mathrm{CP} 3$ & .836 & Reflective & & \\
\hline \multirow[t]{3}{*}{ IntoPay } & IP1 & .819 & Reflective & .709 & .879 \\
\hline & IP3 & .888 & Reflective & & \\
\hline & IP4 & .816 & Reflective & & \\
\hline
\end{tabular}


So it can be said that the indicators used in measuring latent variables have fulfilled convergent validity. Next, a convergent validity test is performed by looking at the average variance extracted (AVE) and testing the reliability based on the value of composite reliability (CR) to increase confidence in the validity and reliability of research.

Based on the test results of convergent validity in table 2, it is known that the AVE value of PriceVal is 0.791, PremFit is 0.762, AttFree is 0.608, AttPrem is $0.854, \mathrm{CogPrem}$ is 0.698 and IntoPay is 0.709 . The recommended AVE value is above 0.5 [12]. It is known that all AVE values> 0.5, which means that they have met the convergent validity requirements based on AVE.

The reliability test results are based on CR values; it is known that the CR value of PriceVal is 0.919 , PremFit is 0.865 , AttFree is 0.861, AttPrem is 0.921, CogPrem is 0.822 and IntoPay is 0.879 . The recommended CR value is greater than 0.7 [12]. It can be seen all CR values> 0.7 , meaning that they have met the reliability requirements based on CR.

\subsection{Hypothesis Testing}

After testing the validity and reliability of the measurement model, then hypothesis testing will be conducted. In Figure 2, it can be seen that the value of the path coefficient from AttFree to AttPrem is 0.598, which is positive. This means that AttFree has a posi-tive effect on AttPrem. Given a P-Values value $<0.001$, which also means <a significance level of 0.05 , the hypothesis (1) is proven where AttFree has a positive effect on AttPrem.

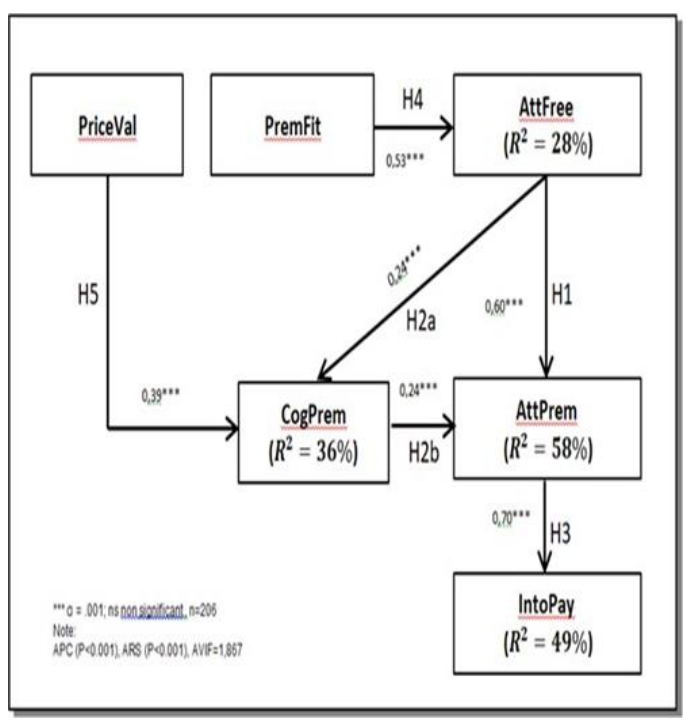

Figure 2 Hypothesis Test Results

The value of the path coefficient from AttFree to CogPrem is 0.244 , which is positive. This means that AttFree has a positive effect on CogPrem. Given a PValues value $<0.001$, which also means < a significance level of 0.05 , the hypothesis ( $2 a$ ) is proven where AttFree has a positive effect on CogPrem.

The value of the path coefficient from CogPrem to AttPrem is 0.240 , which is positive. This means that CogPrem has a positive effect on AttPrem. Given a PValues value $<0.001$, which also means $<$ a significance level of 0.05 , the hypothesis (2b) is proven where CogPrem has a positive effect on AttPrem. The path coefficient value from AttPrem to IntoPay is 0.703 , which is positive. This means that AttPrem has a positive effect on IntoPay. Given a P-Values value $<0.001$, which also means <a significance level of 0.05 , then hypothesis (3) is proven where AttPrem has a positive effect on IntoPay.

The value of the path coefficient from PremFit to AttFree is 0.528 , which is positive. This means PremFit has a positive effect on AttFree. It is given a P-Values value $<0.001$, which also means < a significance level of 0.05 , then the hypothesis (4) is proven where PremFit has a positive effect on AttFree. Finally, the value of the path coefficient (path coefficient) from PriceVal to CogPrem is 0.394 , which is positive. This means PriceVal has a positive effect on CogPrem. Given the P-Values value $<0.001$, which also means <a significance level of 0.05 , then the hypothesis (5) where PriceVal has a positive effect on CogPrem.

\subsection{Goodness of Fit}

In terms of ensuring that the results of hypothesis testing using the research model that has been developed are not biased, it is necessary to test the suitability of the model. According to Sholihin, M., \& Ratmono, D. (2013) [12] that a research model can be said to be "fit" if the pvalue of the average path coefficient (APC) and average $\mathrm{R}$ - Squared (ARS) is smaller than the level of significance $(<0.05)$, then the value from the average block VIF (AVIF) does not exceed 3.3.

Based on Figure 2 it can be seen that the p-value of APC and ARS is $<0.001$ and is smaller than the level of significance $(<0.05)$; besides that the value of AVIF has also fulfilled the requirements $(1,867<3.3)$. So it can be said that the model used in this study has fulfilled the Goodness of Fit element.

\subsection{Discussion}

Hypothesis (1) is proven, meaning that interest in using free software (attitude-free) can en-courage user interest in using premium software (attitude Premium). This result is different from the findings of Wagner, T.M., et al. [1] who found no evidence regarding the relationship between attitude-free and attitude premium. In general, the behavior of software users is also 
influenced by the trial version they try before purchasing the full version of the software.

Software Providers can influence users through a series of promotions by introducing their products free of charge to users, so that when users have a memorable experience with the software they offer, it is certainly expected that users will be more attached to the product and need to acquire the software into the full version to support business needs users of the software.

Anon [7] states that the free version of a software product can be a marketing strategy for software developers. The free version is a form of trial demo given to customers so they can test the features contained in the software and feel the benefits of a software product. Through free version software, developers market their products to be felt by users spread all over the world. The more people try the free version of the software, the more opportunities there are for the premium version to sell.

Hypothesis (2a) is proven, meaning that the interest in using free software (attitude-free) can increase user awareness related to the differences between the features provided in the free version and not as complete as the premium version (Cognition Premium). These results also con-firm the findings of Wagner, T.M., et al. [1] who found evidence of a positive relationship between attitude-free and cognition premium.

Veit, D., et al. [13] states that in conditions where people tend to be forced to buy software, recognition of the quality of the premium version of the software can be the main reason for users to change their logic from not wanting to buy to be interested in experiencing the experience of the premium version because of the high quality and the benefits they feel from the software product.

Hypothesis (2b) is proven; these results confirm the findings of Wagner, T.M., et al. [1] where there is a positive influence between cognition premium and attitude premium. If the user al-ready has an awareness of the different features offered and the benefits of the software they have tried, then the user will enter a phase where they are so interested in using the premium version of the software they choose, even though the user has to make sacrifices in the form of subscription fees in order to continue to enjoy the benefits and quality they get from a software product.

Wagner, T.M., et al. [1] found conditions where users were forced to pay for a service; voluntary awareness of the product also has its own role. Unlike attitudes, awareness is more likely to describe the thoughts and experiences of users of the service they choose. So with awareness, users can voluntarily choose the premium version of the software because of the positive experience they have felt.
Hypothesis (3) is proven, meaning that users who have been interested in premium version software (attitude Premium) will tend to take the decision to make a purchase (Intention to Pay) immediately. This finding is in accordance with Wagner, T.M., et al. [1]. The decision to buy a li-censed accounting software is certainly greatly influenced by how much benefit and quality is offered by the software which is the reason for users to make an important decision in acquiring the premium version.

The DMH model provides a good overview of how customers' attitudes determine their final motivation to switch to the premium version of the software immediately. Every decision taken by a user is greatly influenced by their perception of a service they receive. Through a freemium software strategy software development companies can easily introduce their products by providing direct experience to consumers. It can be said that freemium software is a potential form of modern advertising in the current digital era. Users who have experienced of a piece of software will easily switch to the premium service version that they have finally chosen.

Hypothesis (4) is proven, meaning that the user's perception related to the level of the gap between free and premium content of a software (perceived premium fit) can affect the behavior of free software users (attitudefree). Wagner, T.M., et al. [1] states that software developers try to provide a fundamental difference between the free version and the premium version of the software to avoid users becoming reluctant to use the premium version because they think that the free version can facilitate all their desires.

Currently, many software developers with a freemium strategy realize that the different con-tent, features, and functions offered between free software and premium software need to be improved. The similarity of functions and features offered can cause users to prefer the free version of the software. This certainly can be a problem in decline in sales for software development companies. With the restrictions on the free version of software such as restricted functions, incomplete reporting, data restrictions, and limited usage periods, it is judged to be able to persuade users to switch to the premium version.

It should be understood that if the similarity between free and premium software is very high or the features offered are not much different, it will cause the behavior of users to prefer the free version offered. Meanwhile, the free version of the software is designed with the aim of being a promotional tool to improve the main services offered by software developers. Therefore, every software developer needs to add an exclusive touch of the premium version they offer, so users feel the need to switch to the premium version. 
Hypothesis (5) is proven, these results confirm the findings of Wagner, T.M., et al. [1] where there is a positive influence between perceived software price (perceived price value) on user awareness of the different features offered by the premium version far more complete than the free version (cognition premium). The price paid greatly affects the behavior of software users; high prices certainly require far more complete usability than the free version. In making decisions about purchasing software, it is usually inseparable from the price factor (cost) and benefits (benefits) they will get.

Some previous studies found that price is the best comparison for the quality offered by a piece of software, users are likely to have evaluated the advantages of software well, so they give high valuations to premium prices [5][14]. Price and quality are factors that determine the user's awareness to switch to the premium version. If the features offered are in line with the user's expectations, the user will voluntarily choose the premium version of the software.

\section{CONCLUSION}

This study aims to provide empirical evidence about the freemium software strategy which is a new business model in the digital era by applying the DMH (Dual Mediation Hypothesis) model to investigate the effects of the freemium strategy as a promotional tool for software developers that can increase user interest in purchasing device versions licensed premium accounting software in Indonesia.

This study uses 206 samples of respondents from various backgrounds, such as consultants, business owners, managers, and employees who use accounting software in their business activities. Based on the test results, we find evidence that there is a positive influence between attitude-free and attitude premium. In addition, this study proves that the differences in features offered between the free version and the maximum software can determine user motivation in making decisions to buy premium services. This research shows that the price set for software can also influence the decision to use premium software.

Based on the discussion, the results of the research show that freemium software can be a good marketing strategy for software developers. Through the free version of the software provided to users, it can change the user's behavior to switch to a complete premium version, so that it can effectively increase software sales in the current modern era. In addition, the sensitivity test results showed that the CogPrem latent variable was not proven to be a mediating variable for the effect of the AttFree variable on AttPrem. These results can be considered in the formation of the DMH model in future research.

\section{ACKNOWLEDGMENTS}

This research received funding assistance from LPPM Jambi University through its cluster of excellence in applied research. We want to thank Jambi University for giving us much support. Thanks to the other parties involved in this research, especially the reliable research team and the very friendly respondents. We hope that this research can become useful knowledge for the development of science, institutions, and our students.

\section{REFERENCES}

[1] T. M. Wagner, A. Benlian, \& T. Hess (2014) Converting Freemium Customers from Free to Premium - the Role of the Perceived Premium Fit in the Case of Music as a Service. Electron Markets, 24, pp.259-268. DOI: https://doi.org/10.1007/s12525- 014-0168-4

[2] K. Lyons, P. Messinger, R. Niu, \& E. Stroulia. (2012) A Tale of Two Pricing Systems for Services. Information Systems, and e-Business Management, 10(1), pp.19-42. DOI: https://doi.org/10.1007/s10257-010-0151-3

[3] -

[4] L. J. Albert, N. Aggrawal, \& T. R. Hill, (2014) Influencing Customer's Purchase Intentions Through Firm Participation in Online Consumer Communities. Electron Markets, pp.285-295. DOI: https://doi.org/10.1007/s12525-014-0169-3

[5] I. Lopez, \& S. Ruiz, (2011) Explaining Website Effectiveness: The Hedonic-Utilitarian Dual Mediation Hypothesis. Electronic Commerce Research and Applications, 10(1), ,pp.4958.DOI: https://doi.org/10.1016/j.elerap.2010.04.003

[6] F. Wilson (2006) A freemium business model, $03-$ 24-2012. Retrieved from http://www.avc.com/a_vc/2006/03/the_freemium_ bu.html

[7] Anon (2009) Free: the future of a radical price. Choice Reviews Online, 47(04), pp.47-2102-472102. DOI: http://dx.doi.org/10.5860/choice.472102

[8] E.B.Seufert (2014) The Freemium Business Model. Freemium Economics, pp.1-27.DOI: http://dx.doi.org/10.1016/b978-0-12-4166905.00001-4

[9] R.E. Petty, \& J.T. Cacioppo (2018) Attitudes and Persuasion, 2018, DOI: http://dx.doi.org/10.4324/9780429502156

[10] H.K. Cheng, \& Q.C. Tang (2010) Free trial or no free trial: Optimal software product design with 
network effects. European Journal of Operational Research, 205(2), pp.437-447. DOI: http://dx.doi.org/10.1016/j.ejor.2010.01.014

[11] E. J. Karson, \& R. J. Fisher (2005) Intentions to Return to the Website: Extending the Dual Mediation Hypothesis. Journal of Interactive Marketing, 19(3), pp.2-14. DOI:

https://doi.org/10.1002/dir.20040

[12] M. Sholihin, \& D.Ratmono, (2013)Analisis SEMPLS dengan WarpPLS 7.0: untuk Hubungan Nonlinier dalam Penelitian Sosial dan Bisnis. Penerbit Andi.

[13] D. Veit, E. Clemons, A. Benlian, P. Buxmann, T. Hess, D. Kundisch, \& M. Spann (2014) Business Models. Business \& Information Systems Engineering, 6(1), 2014, pp.45-53. DOI: https://doi:10.1007/s12599-013-0308-y

[14] V. Venkatesh, J. Y. L. Thong, \& X. Xu (2012) Consumer Acceptance and Use of Information Technology: Extending the Unified Theory of Acceptance and Use of Technology. MIS Quarterly, 36(1),

pp.157-178.DOI:

https://doi.org/10.2307/41410412 